\title{
Trichoscopy in anagen effluvium: Extensive peripilar sign
}

\section{Malakar Subrata, Mehta Purva, Malakar Surit}

\author{
Rita Skin Foundation, Kolkata, India
}

Corresponding author: Dr. Mehta Purva, E-mail: purvamehta86@gmail.com

Sir,

Peripilar sign also called as perifollicular hyperpigmentation or brown perifollicular discolouration on trichoscopy, denotes a brown halo surrounding a hair follicle. It corresponds to perifollicular lymphocytic infiltrate [1,2]. It is known to occur in conditions like androgenetic alopecia and telogen effluvium. In these conditions, when the peripilar sign is extensively seen on trichoscopy, it is regarded as a poor prognostic factor for hair loss $[3,4]$. Peripilar sign in also seen on healthy scalp where the perifollicular discolouration is limited to a few hair follicles $(<5 \%)$ [3].

We present two cases of anagen effluvium where the peripilar sign was extensively seen on trichoscopy (Figs. 1-4).

As mentioned before, peripilar sign has been documented in androgenetic alopecia and telogen effluvium. There are various hypotheses that could explain the occurrence of peripilar sign in anagen effluvium. Although perifollicular inflammation is known to be the cause of peripilar sign; its etiopathogenesis is still unknown in its entirety. It has been postulated that perifollicular inflammation could result due to the effect of ultraviolet rays, chemical exposure, melanocytes etc $[5,6]$.

Patients suffering from anagen effluvium have significant hair loss thus exposing a large surface area of their scalp to ultraviolet rays. This additional exposure and effect of ultraviolet rays could be a contributing factor to perifollicular inflammation in anagen effluvium.
Inui et al have already speculated that the occurrence of peripilar sign in Asians is a result of postinflammatory hyperpigmentation [7]. In our case, both patients being Asian, peripilar sign could be attributed to the presence of melanocytes. This finding is akin to honeycomb pigmented network, which is a trichoscopic finding on

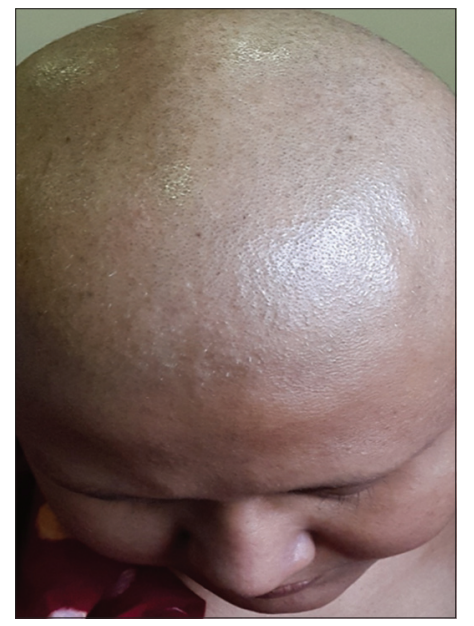

Figure 1: Anagen effluvium in a patient post chemotherapy.

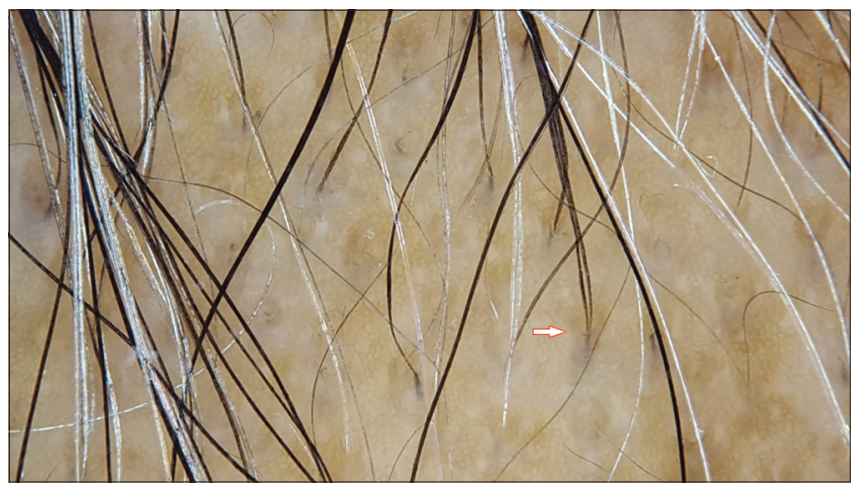

Figure 2: Extensive perifollicular brown pigmentation/peripilar sign evident on trichoscopy in the same patient. 


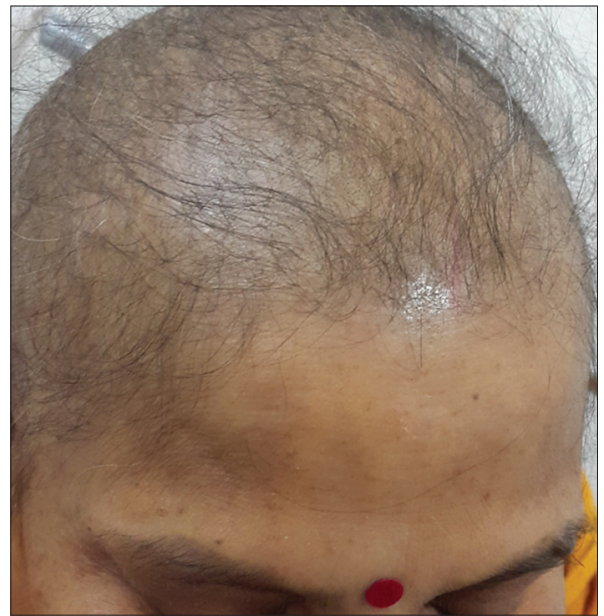

Figure 3: Anagen effluvium following chemotherapy.

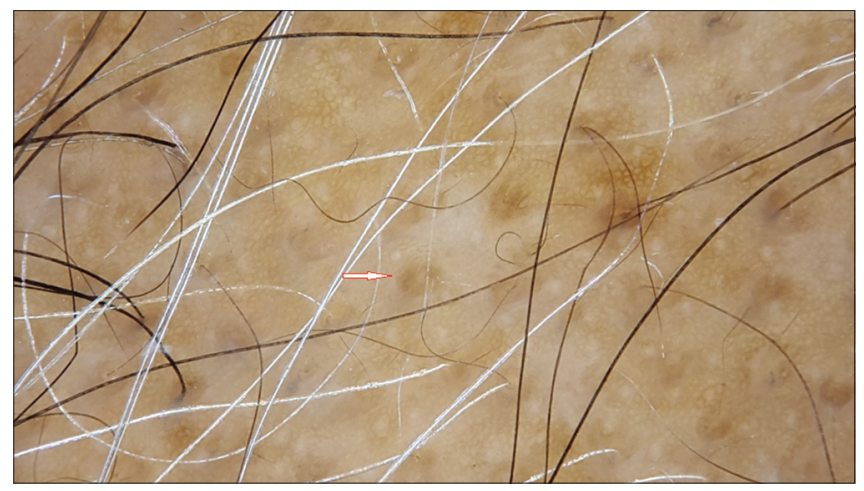

Figure 4: Extensive peripilar sign in the same patient of anagen effluvium.

normal scalp. It is essentially a mosaic of contiguous brown rings but is commonly seen in people with darker skin or in bald Caucasians who have had chronic sun exposure [8].

Our patients were subjected to intensive chemotherapy which resulted in anagen effluvium. Thus, prolonged chemical exposure could be a causative factor for peripilar sign in anagen effluvium as mentioned before $[5,6]$.

To the best of our knowledge this is the first report of peripilar sign in anagen effluvium. However further evaluation of subjects with anagen effluvium is necessary to document not only the presence of peripilar sign but also its origin and prognostic significance.

\section{REFERENCES}

1. Tosti A. Hair shaft disorders. In: Tosti A, editor. Dermoscopy of Hair and Scalp: Pathological and Clinical Correlation. Illustrated ed. USA: CRC Press; 2007. pp. 51-53.

2. Tosti A, Duque-Estrada B. Dermoscopy in hair disorders. J Egypt Womens Dermatol Soc. 2010;7:1-4.

3. Rakowska A, Slowinska M, Olszewska M, Rudnicka L. Androgentic alopecia. In: Rudnicka L, Olszewska M, Rakowska A, editors. Atlas of trichoscopy. London: Springer; 2012. p. 229-230.

4. Rakowska A, Olszewska M, Rudnicka L. Telogen effluvium. In: Rudnicka L, Olszewska M, Rakowska A, editors. Atlas of trichoscopy. London: Springer; 2012. p. 243.

5. Won CH, Kwon OS, Kim YK, Kang YJ, Kim BJ, Choi CW, et al. Dermal fibrosis in male pattern hair loss: A suggestive implication of mast cells. Arch Dermatol Res. 2008;300:147-52.

6. Jaworsky C, Kligman AM, Murphy GF. Characterization of inflammatory infiltrates in male pattern alopecia: Implications for pathogenesis. Br J Dermatol. 1992;127:239-46.

7. Inui S, Nakajima T, Itami S. Scalp dermatoscopy of androgentic alopecia in Asian people. J Dermatol. 2009;36:82-5.

8. Braun RP, Rabinovitz HS, Oliviero M, Kopf AW, Saurat JH. Dermatoscopy of pigmented skin lesions. J Am Acad Dermatol 2010;63:721-2

Copyright by Malakar Subrata, et al. This is an open access article distributed under the terms of the Creative Commons Attribution License, which permits unrestricted use, distribution, and reproduction in any medium, provided the original author and source are credited.

Source of Support: Nil, Conflict of Interest: None declared. 